\title{
Enhanced Immobilization of Polycyclic Aromatic Hydrocarbons in Contaminated Soil Using Forest Wood-Derived Biochar and Activated Carbon under Saturated Conditions, and the Importance of Biochar Particle Size
}

\author{
Ali Daryabeigi Zand ${ }^{1 *}$, Peter Grathwohl ${ }^{2}$ \\ ${ }^{1}$ Faculty of Environment, University of Tehran, \\ 23, Ghods St., 141556135 Tehran, Iran \\ ${ }^{2}$ Center for Applied Geosciences (ZAG), University of Tübingen, \\ Hölderlinstr. 12, 72076 Tübingen, Germany
}

Received: 17 September 2015

Accepted: 11 October 2015

\begin{abstract}
Leaching behavior of organic contaminants such as polycyclic aromatic hydrocarbons (PAHs) can be altered in the presence of organic amendments through enhanced sorption of PAHs to the amended soil. The aim of the present study was to investigate the influence of biochar in two forms (i.e., crushed and pulverized), and granular activated carbon on immobilization and leaching behavior of selected PAHs from contaminated soil into water using the column leaching test. The influence of biochar particle size on leaching behavior of PAHs in biochar-amended soil was also evaluated for the first time in this study. Results showed relatively high initial concentrations of naphthalene, fluorene, and pyrene for unamended column (B1). Strong sorption of all PAHs to soil was observed in this study. At the end of the experiment less than one percent of the solid phase content of the sum of PAHs was released into water in columns B3 and B4. Change in pH due to the application of organic amendments did not affect PAH leaching results. The addition of pulverized biochar and granular activated carbon to soil remarkably reduced mobilization and leaching of the studied PAHs in most cases; however, higher molecular weight PAHs (i.e., pyrene, benzo(b)fluoranthene, and indeno(1,2,3cd)) were mobilized in the presence of crushed biochar in soil. The controlling role of biochar particle size on mobilization and release of PAHs in soil was observed. The application of pulverized biochar and activated carbon increased colloid content of the column effluents while reducing their dissolved organic carbon (DOC) content, suggesting a more significant role of colloid-facilitated transport than DOC-associated transport of PAHs in their leaching from carbon-amended soils, particularly for higher molecular weight PAHs. Based on the obtained results, pulverized biochar and granular activated carbon demonstrated promising and comparable performance in immobilizing PAHs in soil and reducing their leaching from soil into water through enhanced sorption of PAH compounds, which is markedly favorable in terms of soil remediation.
\end{abstract}

Keywords: biochar, activated carbon, soil, polycyclic aromatic hydrocarbons, column leaching test

*e-mail: adzand@ut.ac.ir 


\section{Introduction}

Polycyclic aromatic hydrocarbons (PAHs) are a group of organic contaminants characterized by their high hydrophobicity, resistance to biodegradation, and carcinogenic properties [1]. The widespread occurrence of hydrophobic organic chemicals such as PAHs in soil is a major environmental problem $[2,3]$. PAHs consist of two or more aromatic rings in their structure and mainly originate from anthropogenic sources, e.g. incomplete combustion of fossil fuels, wood burning, and municipal and industrial waste incineration. They can also occur naturally, e.g. during forest fires or by volcanoes [4]. Some PAHs are listed on the U.S. Environmental Protection Agency (EPA) priority pollutant list due to their toxic and mutagenic effects [5]. Probable human health effects of PAHs include, but are not limited to, skin damage, DNA damage, birth defects, and cancer development $[6,7]$.

Sorption capacity of soils plays an important role in controlling the bioavailability and fate of organic contaminants in the environment [8]. Leaching of PAHs from soil is a major concern at most contaminated sites due to the risk of groundwater pollution. Contaminated groundwater poses a serious risk for drinking water supplies [9]. Conventional soil remediation technologies mainly rely on excavation and landfilling, which are both costly and often environmentally disruptive [10]. Development and examination of effective and environmentally friendly approaches is necessary to control the mobilization and migration of contaminants from contaminated soils to groundwater resources.

Organic amendment of soil can change soil structure, transport, and sorption characteristics. For instance, organic amendment of soil may increase porosity and water retention, alter pore size distribution, and reduce bulk density of soil [11]. Distribution coefficient $\mathrm{K}_{\mathrm{d}}$, which is the ratio of the concentration of a contaminant in solid phase (e.g., soil to the equilibrium concentration in the contacting liquid phase, e.g., water is directly proportional to the fraction of organic carbon in the soil [12]) and can be enhanced significantly when carbon-rich materials are added to the soil. Sorption of hydrophobic organic compounds (HOCs) on black carbon, including char, charcoal, fly ash, and soot-like materials, might be up to 10-1,000 times greater than that of soil organic matter, and have been reported in the literature as a treatment method to further restrict desorption and mobilization of organic contaminants in soil [13-15]. The distribution of organic contaminants such as aromatic hydrocarbons between solid phase and water solution is mainly controlled through the absorption to both organic matter of soil and black carbon. It has been shown in a number of studies that adsorption to black carbon dominates the interaction between organic contaminants and soil organic matter [15].

Biochar is a carbon-rich product produced by heating biomass in a low/no oxygen environment (pyrolysis). The use of biochar as a soil amendment has increased during the last decade because of its potential for improving soil fertility and long-term soil carbon sequestration, thereby reducing the amount of carbon dioxide released to the atmosphere. Biochar is mainly composed of recalcitrant carbon structures that prevent its decomposition. Therefore, the addition of biochar to soil can provide long-term carbon storage [16-18]. It is mainly used as a soil amendment to improve soil fertility and crop production, but its application as a novel technology to remediate contaminated sites has received increasing attention in recent years because of its strong affinity to organic contaminants such as PAHs [13]. Slow desorption of organic contaminants such as PAHs and pentachlorophenol (PCP) due to their strong sorption to carbonaceous material in soil has been reported by other authors [11, 13-14, 19]. Activated carbon, which has been applied for various environmental purposes, is also a strongly sorbing carbonaceous material produced from incomplete combustion of organic materials like coal or biomass, followed by chemical or steam activation of charred residues to increase surface area [19-21]. Several studies have shown that activated carbon and biochar are able to reduce bioavailability and toxicity of organic contaminants [22-24]; however, their influence on leaching and release of persistent organic contaminants, e.g., PAHs from soil, has not been clearly identified. Chars and activated carbons can be used to modify sorption behavior of organic contaminants such as PAHs, thereby modifying their leaching behavior.

The main objective of this study is to investigate the influence of forest wood-derived biochar and activated carbon on leaching behavior of PAHs from soil into water. Biochar was applied to soil in two different forms (i.e., crushed and pulverized) in order to evaluate the influence of biochar particle size on PAH mobilization and leaching from soil. To the best of our knowledge, the effect of biochar particle size on leaching behavior of PAHs in a biochar-amended contaminated soil has rarely been studied. Colloid-facilitated transport of PAHs under the effect of organic amendment in soil has also been addressed in the preset study. Column leaching test as a powerful tool to evaluate close-to-field leaching behavior of PAHs was conducted in this study to provide insight into the leaching and release of selected PAHs from unamended and amended soils.

\section{Materials and Methods}

\section{Soil, Biochar, and Activated Carbon}

Reference-contaminated soil with particle sizes less than $2 \mathrm{~mm}$ and particle density of $2.65 \mathrm{~g} \mathrm{~cm}^{-3}$ was provided from the Federal Institute for Materials Research and Testing (BAM) in Berlin. Forest wood-derived biochar with carbon content of $79.5 \%$ and bulk density of $1.5 \mathrm{~g} \mathrm{~cm}^{-3}$ was evaluated in this study. Forest wood-biochar used in this research was produced under the pyrolytic temperature of $612-741^{\circ} \mathrm{C}$. Biochar chips were air-dried for a week. Some of them were crushed in a ceramic mortar using a pestle and passed through a $2 \mathrm{~mm}$ sieve before 
Table 1. Comparison of column test with batch test [29].

\begin{tabular}{|c|c|c|}
\hline Parameters & Column test & Batch test \\
\hline Testing period & Short- and long-term (days to months) & Short-term (days) \\
\hline Application of results & More specific scenario & Depending on type of batch test \\
\hline L/S ratio & Relatively low (close to field condition) & $\begin{array}{c}\text { Relatively high (to estimate maximum amounts } \\
\text { of pollutants to be leached) }\end{array}$ \\
\hline $\mathrm{pH}$ control & Material dictates its own chemical environment & Easy-to-control pH with appropriate chemicals \\
\hline
\end{tabular}

mixing with contaminated soil. The rest of the air-dried biochar chips were milled using a zirconium oxide planet ball mill to yield pulverized biochar (particle size less than $1 \mu \mathrm{m})$ to be mixed with contaminated soil and placed in the columns. Filtrasorb TL 830 granular activated carbon (GAC) purchased from Chemviron carbon containing $890 \mathrm{mg} / \mathrm{g}(89 \%)$ organic carbon with BET surface area of $922 \mathrm{~m}^{2} \mathrm{~g}^{-1}$ was used in this research.

\section{Preparation of Columns and Leaching Experiment}

The most commonly applied leaching tests in Germany were batch tests with different liquid-tosolid ratios. Recently a paradigm shift has occurred in leaching tests from batch tests toward column tests [25]. Findings of the recent German joint research project "Sickerwasserprognose" demonstrated that the column leaching test is suitable for evaluating leaching of both organic and inorganic contaminants [26]. Column leaching tests follow the standard DIN 19528 (2009) [27]. Columns contain the sample, e.g., contaminated soil in a packed bed that is percolated continuously with clean water (mainly from the bottom in order to avoid entrapped air). The effluent water can be collected at desired intervals to be analyzed for potential contaminants. Column leaching tests are therefore performed with the aim of determining the expected contaminant concentrations in water that is in contact with solid materials. Column studies seem to reflect leaching conditions more realistically compared to batch tests [28], which is why this method was used in this study to evaluate leaching behavior of PAHs in soil under various scenarios. In addition, results from the column test are more accurate and representative for the long-term release behaviour of the contaminant in the soil [29]. A brief comparison of column test with batch test is presented in Table 1. Complementary information concerning column leaching test (theory and data) has been reported by Grathwohl and Susset (2009) [26].

Contaminated soil was thoroughly mixed with organic amendments with the following ratios (w/w \%): Column B2: contaminated soil (95\%) and crushed biochar (5\%); Column B3: contaminated soil (95\%) and pulverized biochar (5\%); and Column B4: contaminated soil (95\%) and granular activated carbon (5\%). Column B1 was also prepared containing only contaminated soil as a control treatment. A blank column containing clean quartz sand was also prepared and run to determine probable residual contaminants in order to make sure that there is no residual contamination in the system, e.g., within plastic tubes.

Column tests were performed in glass columns with capacities of approximately $425 \mathrm{~cm}^{3}$. Each column was filled with contaminated soil as well as the mixture of contaminated soil and an organic amendment by placing them into the columns in five sub-layers, which were slightly compacted with the aid of a plastic rammer (200 g) according to DIN CEN/TS 14405 (2004) [30]. The experimental set-up of column tests is presented in Table 2. Glass wool was placed in the bottom of the columns to prevent losses of soil and contamination of leachates with soil particles. Approximately $1 \mathrm{~cm}$ of a quartz sand layer was placed in the bottom of the columns to distribute the water flow through the soil material evenly; then columns were filled by soil or a mixture of soil and organic amendment to a height of approximately $12 \mathrm{~cm}$. An upper quartz sand filter layer was placed above the soil $(1 \mathrm{~cm})$.

The columns were percolated from the bottom to the top in order to minimize trapping of air bubbles. Demineralized water was used in this study to prevent interference with probable non-target ions and compounds in water. A multi-channel peristaltic pump was used to pump demineralized water from the storage tank to the

Table 2. Experimental set-up for the column tests.

\begin{tabular}{|c|c|}
\hline Parameter & Description \\
\hline LS$^{-1}$ ratio & Increasing up to $\mathrm{LS}^{-1}=4 \mathrm{~L} \mathrm{~kg}^{-1}$ \\
\hline Column diameter & $6 \mathrm{~cm}$ \\
\hline Filling height & $12 \mathrm{~cm}$ \\
\hline Filling Volume & $339.12 \mathrm{~cm}^{3}$ \\
\hline Quartz Sand layer height & $1 \mathrm{~cm}$, top and bottom \\
\hline Bulk density & $1.46 \mathrm{~g} \mathrm{~cm}^{-3}$ \\
\hline Porosity & 0.45 \\
\hline Flow rate & $0.4 \mathrm{~mL} \mathrm{~min}{ }^{-1}$, up-flow \\
percolation
\end{tabular}


columns at a constant flow rate (Table 2). At the beginning of the tests, the columns were saturated with the leachant using a higher pump velocity. The columns and the storage tank were connected by PE- (PVC) tubing. The column leaching procedure used in this study followed German industrial standards [27]. Column effluent was collected in dark bottles by connecting the columns to the bottles using a stainless steel tube. Columns were run for different liquid/solid $\left(\mathrm{LS}^{-1}\right.$ ) ratios up to $4 \mathrm{~L} \mathrm{Kg}^{-1}$.

(a)

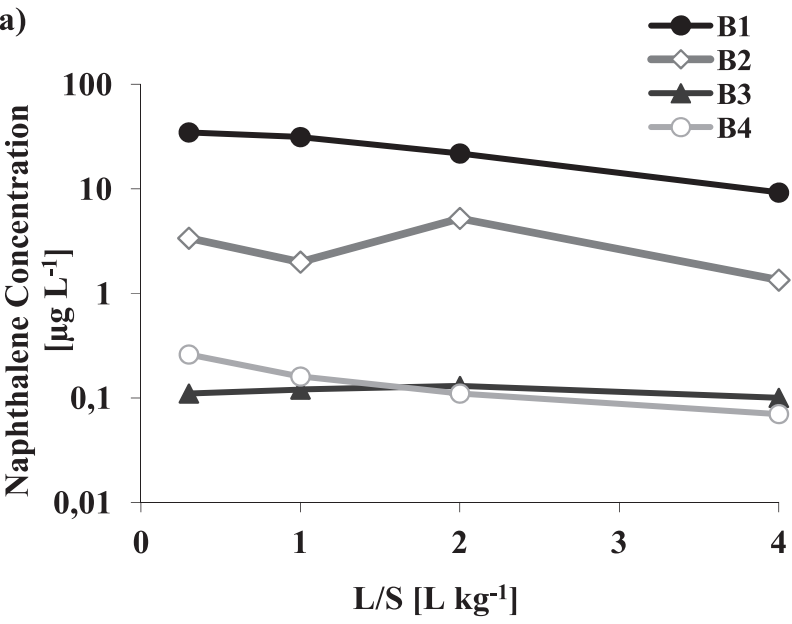

(c)

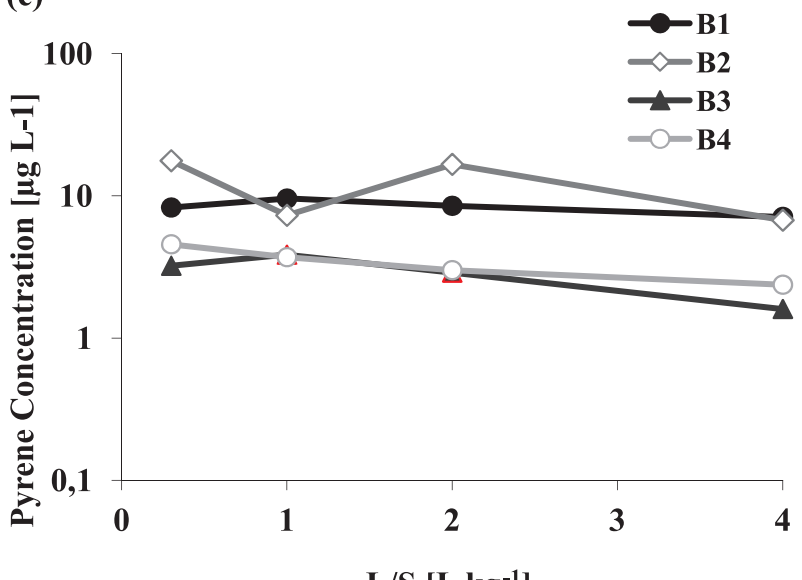

$\mathbf{L} / \mathbf{S}\left[\mathbf{L ~ k g}^{-1}\right]$

(e)

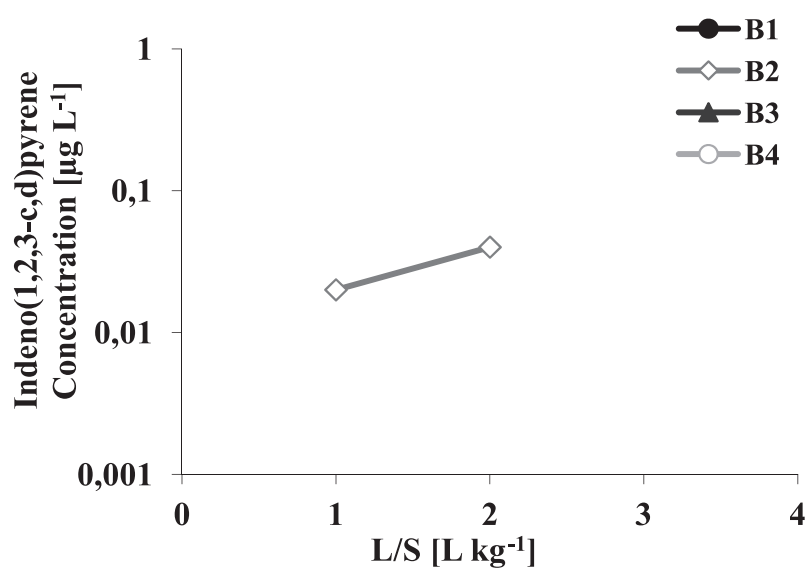

Aqueous Phase Extraction and Analysis of Polycyclic Aaromatic Hydrocarbons

Over the course of the experiment, $30 \mathrm{~mL}$ of initial leached water was collected in separate bottles at assigned $\mathrm{LS}^{-1}$ ratios (to be analyzed for subsequently mentioned parameters), followed by leachate collection in dark bottles containing $10 \mathrm{~mL}$ cyclohexane (solvent) to prevent $\mathrm{PAH}$ loss during the experiment, especially for volatile

(b)

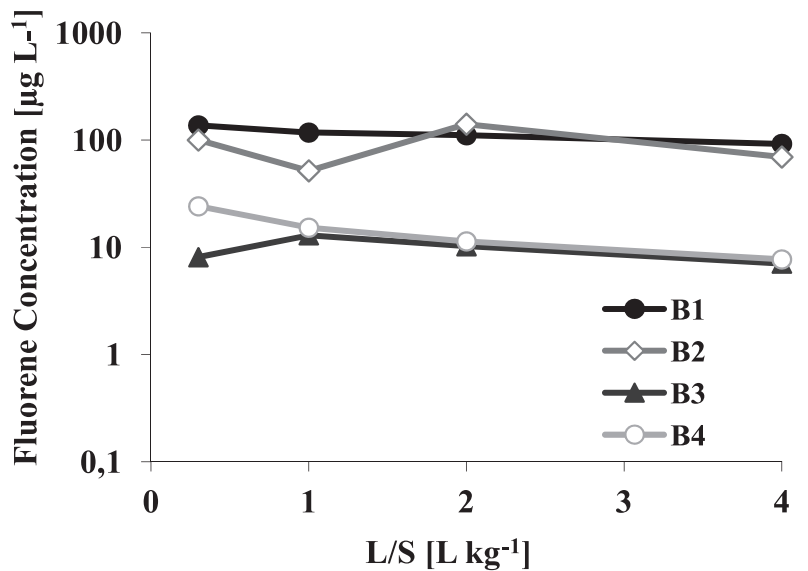

(d)

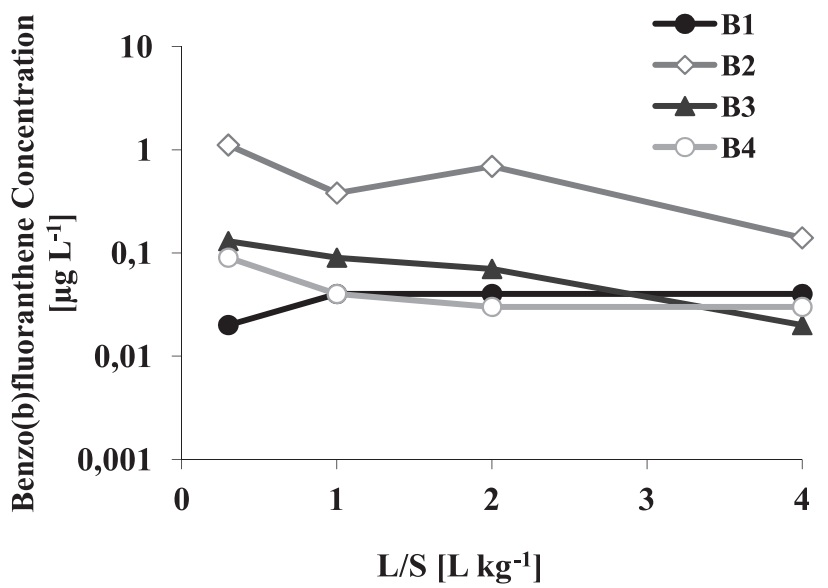

Fig. 1. Concentrations of naphthalene (a), fluorene (b), pyrene (c), benzo(b)fluoranthene (d), and indeno(1,2,3-cd)pyrene in column leachate for unamended soil (B1) and amended soil with crushed biochar (B2), pulverized biochar (B3), and activated carbon (B4). 
PAH compounds (e.g., naphthalene). Internal standard $(10 \mu \mathrm{L})$ was added to the collected water followed by 30 min shaking of bottles in order to facilitate mass transfer of the solutes (PAHs) from water into cyclohexane. Leachates were not filtered as they were already clean due to self-filtration of the packed bed. The PAHs within cyclohexan were then extracted and measured using a GC/MS HP 6890 series. The column used for analysis was DB-5MS and it was $30 \mathrm{~m}$ long, with $0.25 \mathrm{~mm}$ internal diameter and $0.25 \mu \mathrm{m}$ film thickness. Initial column temperature was adjusted to $65^{\circ} \mathrm{C}$ for $4 \mathrm{~min}$, heated to $270^{\circ} \mathrm{C}$ at $10^{\circ} \mathrm{C} \mathrm{min}^{-1}$ and held for $10 \mathrm{~min}$, then to $310^{\circ} \mathrm{C}$ at $10^{\circ} \mathrm{C} \min ^{-1}$ and held for 6.5 .

\section{Solid Phase Extraction and Analysis of Polycyclic Aromatic Hydrocarbons}

In order to find the initial concentration of the PAHs in soil, the accelerated solvent extraction (ASE) technique was used. ASE uses aqueous and organic solvents at elevated temperatures and pressures to achieve the effective removal of analytes from solid matrices in a relatively short period of time with less solvent than the conventional sample extraction methods. Approximately $40 \mathrm{~g}$ of the contaminated soil were placed in the sample cell in order to prepare the samples for ASE, and a $47 \mathrm{~mm}$ diameter filter was used on both ends of the extraction cell. The sample cells were then put into the ASE 300 DIONEX and extracted sequentially with acetone and toluene for $40 \mathrm{~min}$ each. Approximately $50 \mathrm{~mL}$ of extracts were collected in two collecting bottles (one for acetone and the other for toluene solvents). The extracts were quite clean and fine particles settled after around three hours. Extracts from the blanks and the toluene step were used directly for analysis, whereas most of the acetone extracts had to be diluted by factors of 10,20 , or 50 (in order to dilute an acetone sample by a factor of 10 , two $\mathrm{mL}$ extract were mixed with $18 \mathrm{~mL}$ of acetone). Before analysis, $10 \mu \mathrm{L}$ of internal standard was added to $1.5 \mathrm{~mL}$ extract and then the PAHs were measured by the GC/MS HP 6890 series.

\section{Measurement of Turbidity and Dissolved Organic Carbon (DOC)}

Initially collected leachates $(30 \mathrm{~mL})$ at specified $\mathrm{LS}^{-1}$ ratios were measured for turbidity and dissolved organic carbon. An $\mathrm{HACH} 2100 \mathrm{~N}$ Turbidimeter was used to determine turbidity levels in percolates. DOC content of the leachate filtrated by a MILEXHA $0.45 \mu \mathrm{m}$ diameter filter was measured using a HighTOC analyzer (Elementar).

\section{Results}

Naphthalene, fluorene, pyrene, benzo(b)fluoranthene, and indeno(1,2,3-cd) were selected as target PAH compounds in this research. Some chemical properties and the initial concentrations of the target PAH compounds in soil are presented in Tables 3 and 4, respectively. Effluent concentrations of studied polycyclic aromatic hydrocarbons from different columns under various organic amendments are shown in Fig. 1.

\section{Leaching of Naphthalene in Unamended and Organic Amended Soils}

Initially high concentrations of naphthalene were observed in leachate of column B1, where no organic amendment was applied to the contaminated soil. Naphthalene, which has a fused pair of benzene rings in its structure, is known to be the most soluble/volatile PAH compound and dominates the PAH profile in many sites [32]. In the aged soil used in this study naphthalene only contributes to $0.4 \mathrm{mg} \mathrm{Kg}^{-1}$ of solid phase concentration of PAH compounds. Naphthalene concentration in leachate of the contaminated soil without amendment decreased steadily from $34.68 \mu \mathrm{g} \mathrm{L}^{-1}$ at liquid-to-solid ratio of $0.3 \mathrm{~L} \mathrm{Kg}^{-1}$ to $9.22 \mu \mathrm{g} \mathrm{L}^{-1}$ at LS ratio of $4 \mathrm{~L} \mathrm{Kg}^{-1}$, representing a $73.4 \%$ reduction (Fig. 1a).

In this study, biochar was mixed with contaminated soil in two forms - crushed (B2) and pulverized (B3) to examine the effect of adding biochar with different particle sizes on leaching behavior of the selected PAH compounds. Activated carbon was also applied to soil (B4) to study its impact on PAH leaching. Results shows that employing both crushed and pulverized biochar caused considerable reduction in leached amounts of naphthalene at different liquid-to-solid ratios compared to the unamended column. A more than $80 \%$ reduction in naphthalene concentration of percolates was observed in the presence of crushed biochar in soil during the test with the highest value of reduction $(93.6 \%)$ at $\mathrm{LS}$ ratio of $1 \mathrm{~L} \mathrm{Kg}^{-1}$. The addition of $5 \%$ of pulverized biochar reduced naphthalene leaching from contaminated soil remarkably by more than $98 \%$ relative to unamended contaminated soil compared to during the leaching test. Results showed substantially higher performance of pulverized biochar than crushed biochar in terms of immobilization of naphthalene in soil. Activated carbon presented comparable results with pulverized biochar and reduced naphthalene leaching by more than $99 \%$ at various studied LS ratios.

\section{Leaching of Flourene in Unamended and Organic Amended Soils}

Fluorine, a tricyclic PAH compound, is commonly found in soils, sediments, and waters. Fluorene was selected as a model structure in this study since it is present in most PAH mixtures and its structure is found in many mutagenic and/or carcinogenic PAHs, e.g., 2-aminofluorene and 2-nitro-fluorene [33]. The leaching behavior of fluorene from contaminated soil under the effect of organic amendments has rarely been addressed. Fluorene concentration in effluent of column B1 had a decreasing trend as naphthalene; however, reduction of fluorene during the experiment $(24.6 \%$ decrease $)$ was markedly 
less than that of naphthalene, almost by a factor of three.

Applying 5\% crushed biochar did not affect leaching of fluorene to a great extent, while fluorene concentration dropped substantially in the presence of $5 \%$ pulverized biochar in soil. For instance, the initial leached amount of fluorene at LS ratio of $0.3 \mathrm{~L} \mathrm{Kg}^{-1}$ declined from 137.09 $\mu \mathrm{g} \mathrm{L}^{-1}$ in column B1 to $8.09 \mu \mathrm{g} \mathrm{L}^{-1}$ in amended soil with pulverized biochar (94.1\% reduction). The aqueous concentration of fluorene in column B3 declined almost constantly with increasing LS ratios. A considerable increase in fluorene concentration was observed at LS ratio of $2 \mathrm{~L} \mathrm{Kg}^{-1}$, which may be attributed to delayed mobilization and desorption of some adsorbed fluorene from biochar particles as well as colloid-facilitated transport of fluorene. Colloid-facilitated transport of hydrophobic compounds has been reported in the literature [34]. The same increase in fluorene concentration with a lower degree was observed in the presence of pulverized biochar at LS ratio of $1 \mathrm{~L} \mathrm{Kg}^{-1}$. Fig. 1b illustrates that desorption of fluorene and its leaching from soil reduced in the presence of activated carbon during the course of the experiment. Studying the variation of distribution coefficient between soil and organic amendments, e.g., biochar and activated carbon has shown the stronger affinity of phenanthrene, which has three aromatic rings in its structure, to organic amendment rather than soil organic matters and lower desorption of phenanthrene due to the addition of organic amendment to soil [35].

\section{Leaching of Pyrene in Unamended and Organic Amended Soils}

Pyrene with leached amount of $8.27 \mu \mathrm{g} \mathrm{L}^{-1}$ at LS ratio of $0.3 \mathrm{~L} \mathrm{Kg}^{-1}$ showed stronger sorption to soil particles compared to the studied PAHs with two and three benzene rings, i.e., naphthalene and fluorene, respectively. A leached amount of pyrene in unamended soil only decreased by $14.1 \%$ during the course of the experiment. Wick et al. (2011) reported that leaching of PAHs from soil is more likely dominated by colloidal organic matter rather than dissolution in water [4]. Based on the obtained results, however, it would be more conservative to exclude more soluble PAH compounds, e.g., naphthalene.

Utilization of pulverized biochar and activated carbon caused significant reduction in pyrene concentration in percolates of column B3 and B4, respectively, compared to column B1 (Fig. 1c). However, utilization of crushed biochar was not effective in pyrene immobilization in soil. Initial concentration of pyrene in percolate of column B2 $\left(17.63 \mu \mathrm{g} \mathrm{L}^{-1}\right)$ was two and five times more than that of columns B1 and B3, respectively, suggesting that the addition of crushed biochar to soil can significantly mobilize pyrene in soil (at $\mathrm{LS}=0.3 \mathrm{~L} \mathrm{Kg}^{-1}$ ). A decreasing trend in leached concentrations of pyrene was observed in both columns B3 and B4 as LS ratio increased. Concentrations of pyrene in leachates of columns B3 and B4 decreased by $50.3 \%$ and $48 \%$, respectively, during the column leaching test from LS ratio of $0.3 \mathrm{~L} \mathrm{Kg}^{-1}$ to $4 \mathrm{~L}$ $\mathrm{Kg}^{-1}$.

\section{Leaching of Benzo(b)Fluoranthene in Unamended and Organic Amended Soils}

Leaching of benzo(b)fluoranthene from contaminated soil in column B1 was negligible. Initially only $0.0018 \%$ of the initial solid phase concentration of benzo(b) fluoranthene was mobilized in soil and aqueous concentration of $0.02 \mu \mathrm{g} \mathrm{L}^{-1}$ was measured at LS ratio of $0.3 \mathrm{~L} \mathrm{Kg}^{-1}$. Aqueous concentration of benzo(b)fluoranthene increased by a factor of two when LS ratio reached $1 \mathrm{~L} \mathrm{Kg}^{-1}$ and then remained constant to the end of the leaching process.

Organic amendment of soil could not immobilize benzo(b)fluoranthene in this study, except for activated carbon, which slightly reduced mobilization and leaching of benzo(b)fluoranthene from soil (Fig. 1d). The addition of biochar to soil in both forms, i.e., crushed and pulverized forms, increased leaching of benzo(b)fluoranthene from soil. Results showed that leaching behavior of fluorene, pyrene, and benzo(b)fluoranthene have a similar trend, but at different levels in the presence of $5 \%$ crushed biochar in soil (Figs 1b, 1c, and 1d). The observed trend for the studied 3-, 4-, and 5-ring PAHs was comparable with the leaching trend of sum 16 U.S. EPA PAHs (Fig. 3a), where high initial concentrations of the PAHs dropped markedly ( $\mathrm{LS}=1 \mathrm{~L} \mathrm{Kg}^{-1}$ ) before undergoing a sudden increase in aqueous concentrations of PAHs at LS ratio of $2 \mathrm{~L} \mathrm{Kg}^{-1}$. Initial high concentrations of PAHs in percolates followed by a considerable drop may be caused by removal of rapidly desorbing fractions of PAH compounds as also suggested by Marchal et al. (2013) [35], and the establishment of non-equilibrium conditions in column B2. A declining trend again established in aqueous concentrations of PAHs in column percolates from LS of $2 \mathrm{~L} \mathrm{Kg}^{-1}$ to $4 \mathrm{~L} \mathrm{Kg}^{-1}$.

\section{Leaching of Indeno(1,2,3-c,d)Pyrene in Unamended and Organic Amended Soils}

Leaching of indeno(1,2,3-c,d)pyrene (the highest molecular weight PAH among the studied PAH compounds with six condensed rings in its structure) from column B1 did not occur during the leaching process, suggesting an extremely strong sorption of indeno(1,2,3-c,d)pyrene to soil. The U.S. EPA considers benzo(b)fluoranthene and indeno(1,2,3-cd)pyrene to be probable human carcinogens. Fig. 1e illustrates that leaching of indeno(1,2,3-c,d)pyrene from contaminated soil did not occur during the leaching process for amended soil with pulverized biochar (B3) and activated carbon (B4). Indeno(1,2,3-c,d)pyrene was mobilized slightly when crushed biochar was added to the soil.

\section{Release of Individual PAH Compounds in Unamended and Organic Amended Soils}

Fig. 2 illustrates the accumulated leached amount per $\mathrm{kg}$ soil at different LS ratios. Considering solid phase content of the PAHs, results indicate that the cumulative 
release of the studied PAHs decreased with increasing molecular size and hydrophobicity. At the end of the experiment, almost one-third of naphthalene content in soil was mobilized and released into the water in column B1, while only $0.05 \%$ of benzo(b)fluoranthene was mobilized and released from unamended soil, and no mobilization and release was observed for indeno(1,2,3-c,d)pyrene. Cumulative release of naphthalene in percolates of column

(a)

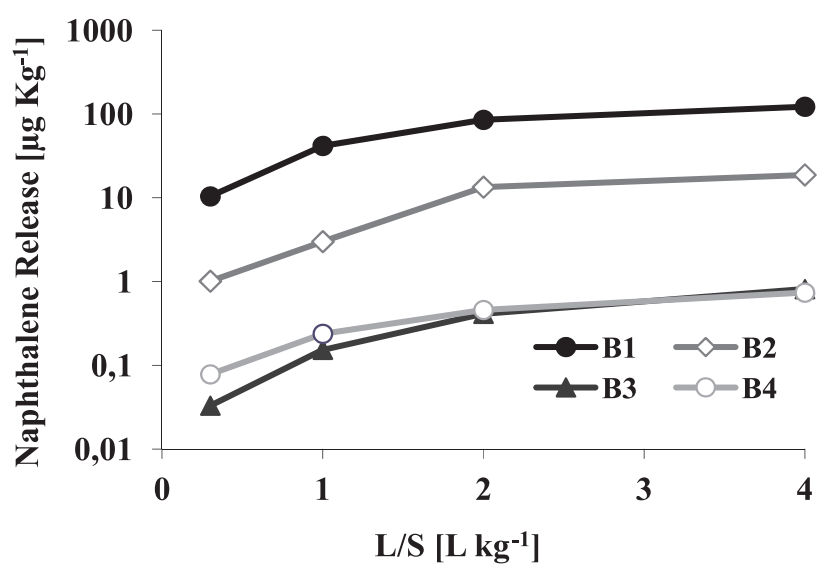

(c)

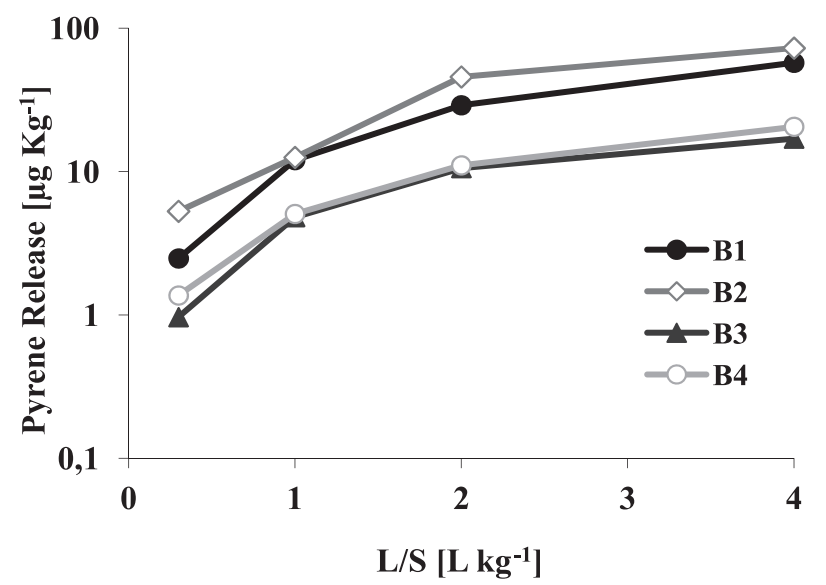

(e)

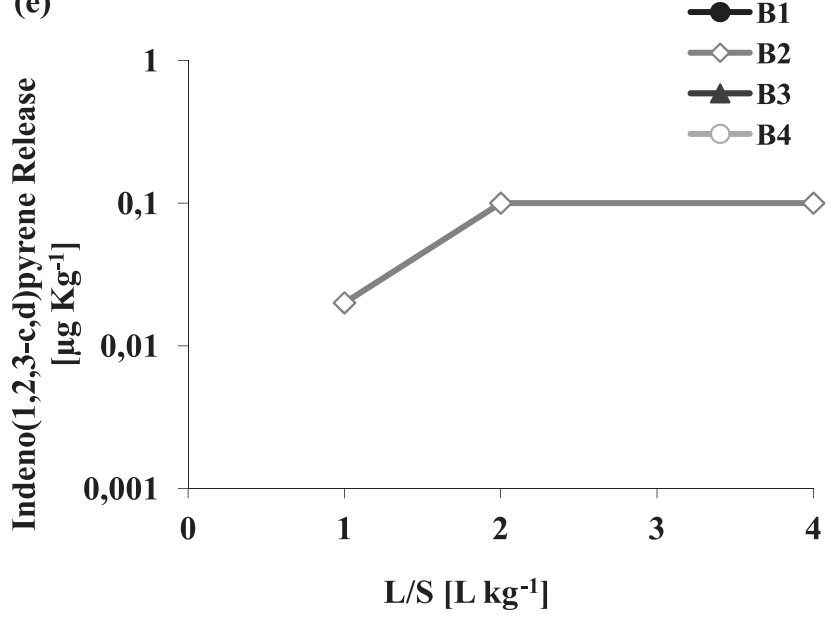

B2 was $18.78 \mu \mathrm{g} \mathrm{Kg}^{-1}$ in the presence of crushed biochar, whereas only $0.81 \mu \mathrm{g} \mathrm{Kg}^{-1}$ naphthalene $(95.68 \%)$ released from column B3 where biochar was used in pulverized form improve in biochar effectiveness with particle size change. Pulverized biochar and activated carbon demonstrated comparable impacts on cumulative release of naphthalene from soil (Fig. 2a). Cumulative release of naphthalene in the presence of $5 \%$ pulverized biochar

(b)

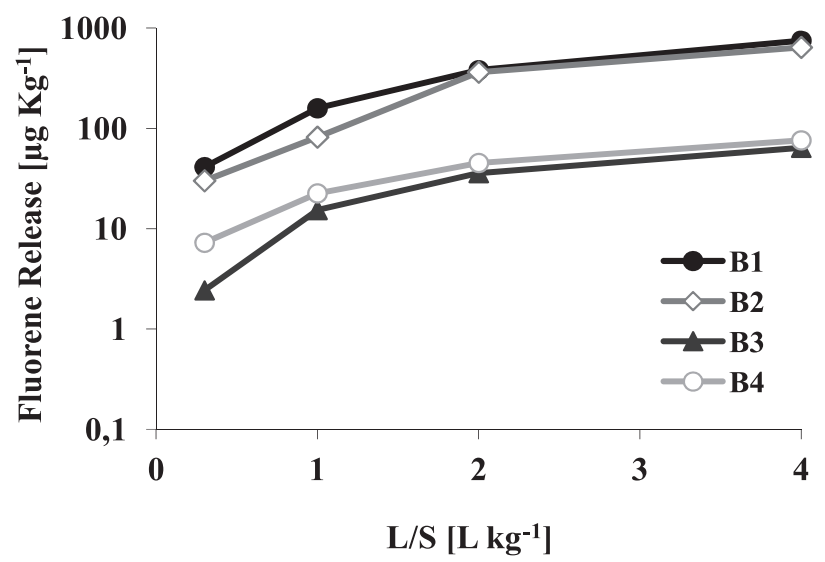

(d)

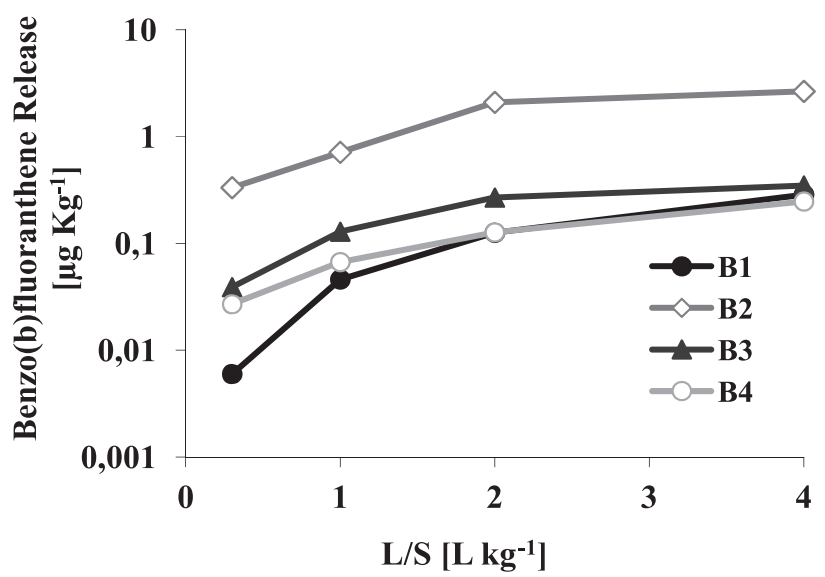

Fig. 2. Cumulative release of naphthalene (a), fluorene (b), pyrene (c), benzo(b)fluoranthene (d), and indeno(1,2,3-cd)pyrene in column leachate for unamended soil (B1) and amended soil with crushed biochar (B2), pulverized biochar (B3), and activated carbon (B4). 
Table 3. Chemical characteristics of the target PAH compounds [4, 31].

\begin{tabular}{|c|c|c|c|}
\hline PAH compound & Molecular Weight $\left(\mathrm{g} \mathrm{mol}^{-1}\right)$ & Water solubility $\left(\mathrm{mg} \mathrm{L}^{-1}\right)$ & Log K$_{\text {ow }}$ \\
\hline Naphthalene & 128 & $3.17 \mathrm{E}+01$ & 3.37 \\
\hline Fluorene & 166.2 & $1.90 \mathrm{E}+00$ & 4.18 \\
\hline Pyrene & 202.3 & $1.32 \mathrm{E}-01$ & 5.18 \\
\hline Benzo(b)fluoranthene & 252.3 & $1.50 \mathrm{E}-03$ & 5.8 \\
\hline Indeno(1,2,3-cd)pyrene & 276.3 & $2.60 \mathrm{E}-04$ & 6.5 \\
\hline
\end{tabular}

and $5 \%$ activated carbon reduced by $99.3 \%$ and $99.4 \%$, respectively, in comparison with that of naphthalene in the absence of organic amendments.

Pulverized biochar demonstrated the best performance in inhibiting the release of fluorene and pyrene from soil among all the amendments. At the end of the experiment, $89.9 \%$ reduction in cumulative release of fluorene was observed in the presence of activated carbon in soil compared to contaminated soil itself, while accumulated release of fluorene declined by $91.5 \%$ in the presence of pulverized biochar (Fig. 2b).

Accumulated release of pyrene increased by $26.6 \%$ when crushed biochar was added to the contaminated soil. Cumulative release of benzo(b)fluoranthene in presence of crushed biochar also enhanced by a factor of nine relative to the unamended soil (B1). Indeno(1,2,3-cd)pyrene, which has the lowest solubility among the studied PAHs (Table 3), was not mobilized and released from columns B1, B3, and B4 (Fig. 2e). However, cumulatively 1.6\% of the solid phase content of indeno(1,2,3-cd)pyrene was released into water in column B2.

\section{Leaching and Release of Total PAHs in Unamended and Amended Soils}

Leached amount of sum 16 U.S. EPA PAHs is shown in Fig. 3a. The total concentration of 16 US EPA PAHs has decreased at the end of the leaching test in all column effluents. Measured concentration of sum 16 US EPA PAHs in percolates dropped from $1063.73 \mu \mathrm{g} \mathrm{\textrm {L } ^ { - 1 }}$ at $\mathrm{LS}=0.3 \mathrm{~L} \mathrm{Kg}^{-1}$ to $665.25 \mu \mathrm{g} \mathrm{L}^{-1}$ at $\mathrm{LS}=4 \mathrm{~L} \mathrm{Kg}^{-1}$, implying $37.5 \%$ reduction in the absence of amendments. Fig. $3 \mathrm{~b}$ reveals that totally $5,607.64 \mu \mathrm{g} \mathrm{Kg}^{-1}$ (ca. $5.6 \mathrm{ppm}$ ) of the 16 U.S. EPA PAHs in contaminated soil (B1) released from solid phase into the water. The application of crushed biochar to soil did not show remarkable influence on immobilization of sum 16 PAHs in soil. Leaching of sum 16 PAHs from column B2 showed similar trend as most of the individual PAHs (Figs 1 and 3a), i.e., a sudden increase in leaching of sum 16 US EPA PAHs from column B2 at $\mathrm{LS}=2 \mathrm{~L} \mathrm{Kg}^{-1}$, was observed for both individual PAHs and sum 16 U.S. EPA PAHs. Concentrations of the sum of 16 U.S. EPA PAH compounds in percolates of columns B3 and B4 declined by $26.2 \%$ and $64.7 \%$, respectively, from LS ratio of $0.3 \mathrm{~L} \mathrm{Kg}^{-1}$ to $4 \mathrm{~L} \mathrm{Kg}^{-1}$.

The addition of pulverized biochar to soil reduced the cumulative release of sum 16 U.S. EPA PAHs by roughly eight orders of magnitude in comparison with unamended soil (Fig. 3b). In column B3 only less than one percent of the initial solid phase concentration of sum 16 US EPA PAHs mobilized and released into water at the end of the experiment. The cumulative release of sum 16 U.S. EPA compounds into water in the presence of activated carbon reduced by $91.9 \%$ compared to that of unamended soil. (a)

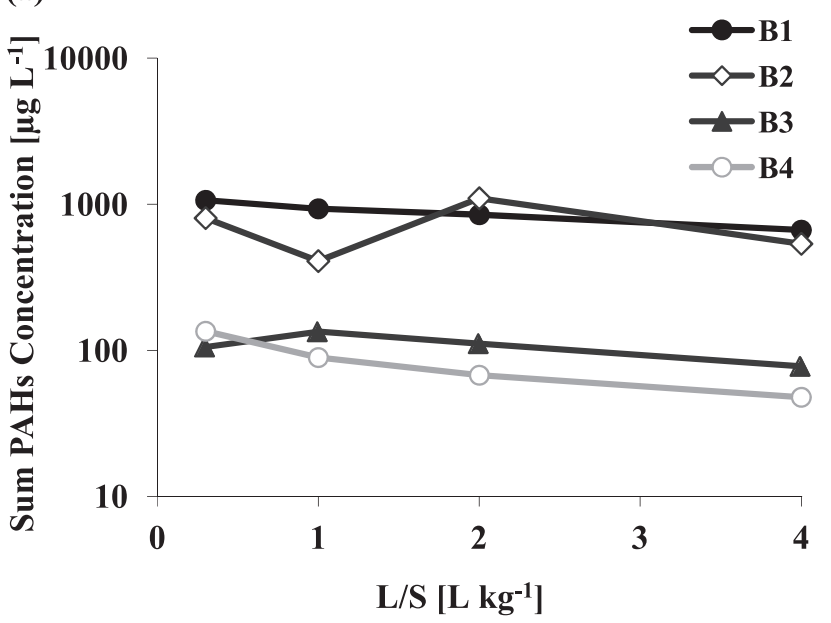

(b)

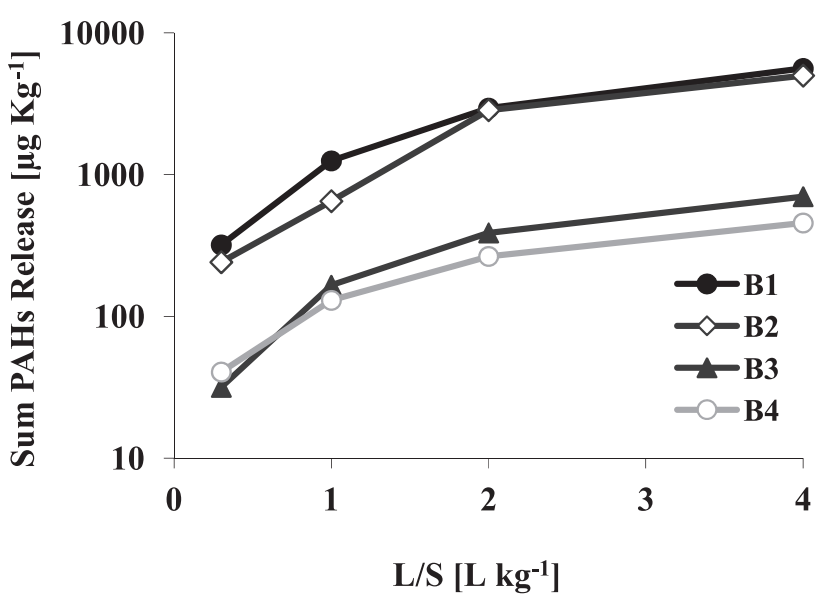

Fig. 3. Concentration (a) and cumulative release (b) of sum 16 EPA PAHs in column leachate for unamended soil (B1) and amended soil with crushed biochar (B2), pulverized biochar (B3), and activated carbon (B4). 


\section{DOC and Turbidity in Leachates of Unamended and Organic Amended Soils}

Dissolved oxygen carbon (DOC) and turbidity measurements were conducted on percolates collected at various LS ratios in this study to see the leaching behavior of DOC and suspended solids from soil under various scenarios studied in this research, as well as to reveal their probable role in leaching the studied PAH compounds. The highest levels of DOC and turbidity were measured at LS ratio of zero $\mathrm{L} \mathrm{Kg}^{-1}$ (i.e., the initially leached water from each column), followed by LS ratio of $0.3 \mathrm{~L} \mathrm{Kg}^{-1}$ in all columns, except turbidity levels for column B3, where the release of suspended solids from soil increased by increasing LS ratios up to $1 \mathrm{~L} \mathrm{Kg}^{-1}$ (Figs. $4 \mathrm{a}$ and $4 \mathrm{~b}$ ). The addition of crushed biochar to soil slightly increased leaching of DOC at LS ratio of zero $\mathrm{L} \mathrm{Kg}^{-1}$. The rapid decline in DOC content of soil, followed by an extended tailing of the DOC concentrations, were observed in all columns, as shown in Fig. 4a. For example, initial DOC concentrations in leachate of column B1 that was $146.78 \mathrm{mg} \mathrm{L}^{-1}$ dropped to $37.5 \mathrm{mg} \mathrm{L}^{-1}$ at LS ratio of $0.3 \mathrm{~L} \mathrm{Kg}^{-1}$ (74.5\% reduction), and finally to $5.73 \mathrm{mg} \mathrm{L}^{-1}$ at LS ratio of $4 \mathrm{~L} \mathrm{Kg}^{-1}$ (96.1\% reduction).

In spite of DOC, the addition of biochar and activated carbon enhanced turbidity levels in the column effluents. Turbidity levels increased when biochar was used in both crushed and pulverized forms (Fig. 4b). Turbidity levels in percolates of column B1 that were packed only with contaminated soil was the lowest among all treatments during the leaching period. In other words, adding biochar in both forms and activated carbon increased turbidity of leachates at various LS ratios. Fig. $4 b$ shows that the initial turbidity levels of leachates increased by a factor of three in the presence of pulverized biochar and activated carbon in soil. The leaching trend of suspended solids was comparable in columns B1, B2, and B4, where a rapid decrease in turbidity of percolates followed by an extended tailing of the turbidity levels was observed. For instance, initial turbidity of leachates from column B4 in which activated carbon was added to soil sharply dropped from 58.9 NTU to $17 \mathrm{NTU}$ at an LS ratio of $0.3 \mathrm{~L} \mathrm{Kg}^{-1}$ and then slowly declined to $5.2 \mathrm{NTU}$ as LS ratio reached $4 \mathrm{~L} \mathrm{Kg}^{-1}$ (more than $90 \%$ overall reduction). Turbidity levels in percolates of column B3 increased with increasing time up to the LS ratio of $1 \mathrm{~L} \mathrm{Kg}^{-1}$. Retarded mobility and leaching of turbidity in the presence of pulverized biochar caused the highest turbidity level (642 NTU) to occur at an $\mathrm{LS}$ ratio of $1 \mathrm{~L} \mathrm{Kg}^{-1}$ in percolates of column B3.

\section{Discussion}

\section{Leaching and Release Behavior of Naphthalene}

In this study, the influence of biochar in two forms (crushed and pulverized) and granular activated on leaching and release of selected PAHs from soil was investigated using the column leaching test. Concentrations of PAH compounds versus liquid-to-solid ratios were plotted instead of time, which is known to facilitate the comparison of data from different types of leaching tests (e.g., batch and column tests) as well as leaching tests of different scales, such as columns with different dimensions [26]. Accumulated release of naphthalene from soil decreased markedly in the presence of all organic amendments used in this research. The impact of the addition of $2 \%$ biochar to soil on the fate of volatile petroleum hydrocarbons (VOCs) was studied by Bushnaf et al. (2011). Biodegradation of VOCs was not inhibited in the presence of biochar in soil. They observed more rapid biodegradation of volatile petroleum hydrocarbons
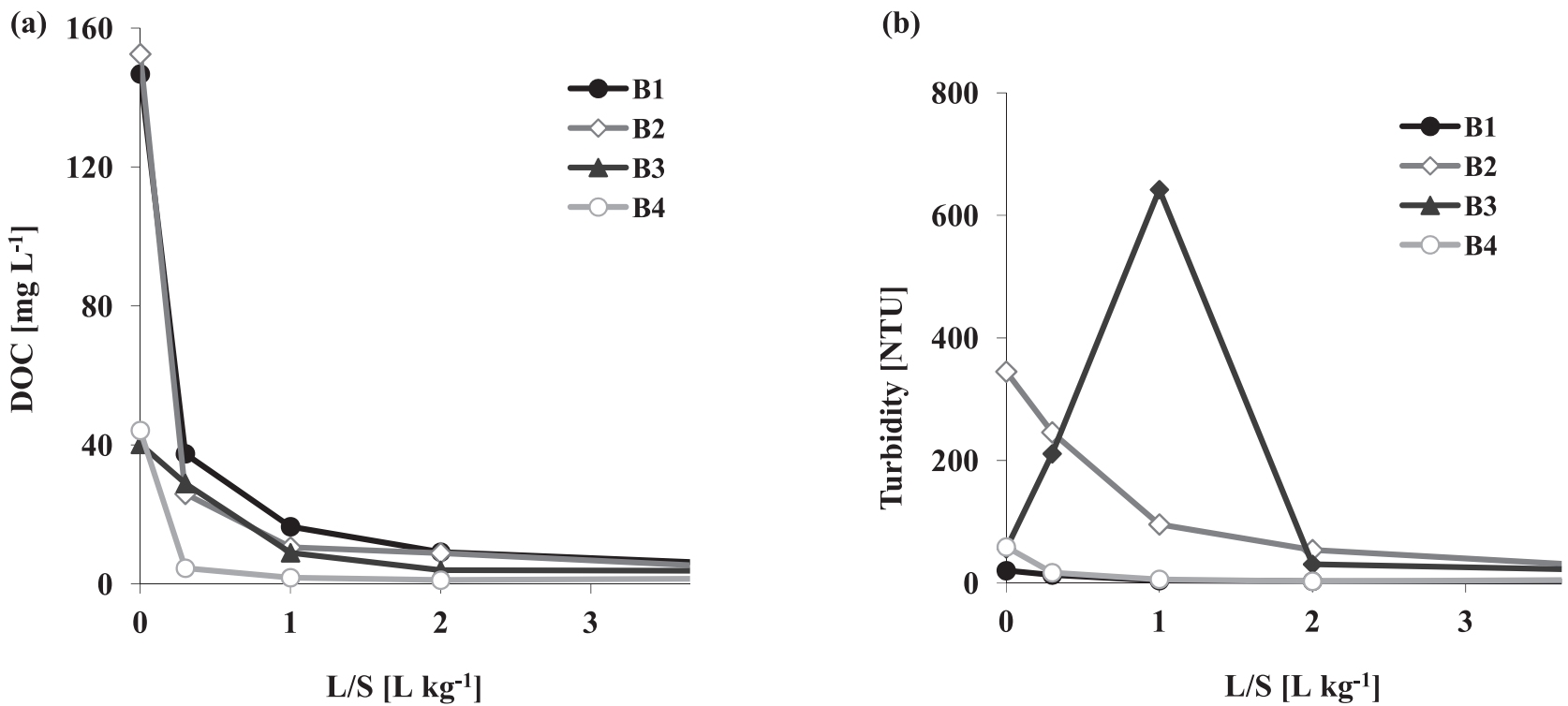

Fig. 4. DOC concentrations (a) and turbidity levels (b) in leachates of unamended soil (B1) and amended soil with crushed biochar (B2), pulverized biochar (B3), and activated carbon (B4). 
Table 4. Initial concentrations of the selected PAHs in the contaminated soil.

\begin{tabular}{|c|c|c|}
\hline PAH compound & $\begin{array}{c}\text { Number of } \\
\text { benzene rings }\end{array}$ & $\begin{array}{c}C_{s}\left(\mathrm{mg} \mathrm{kg}^{-1} \text { dry }\right. \\
\text { soil })\end{array}$ \\
\hline Naphthalene & 2 & 0.4 \\
\hline Fluorene & 3 & 13.24 \\
\hline Pyrene & 4 & 8.27 \\
\hline Benzo(b)fluoranthene & 5 & 0.54 \\
\hline Indeno(1,2,3-cd)pyrene & 6 & 0.06 \\
\hline Sum of 16 EPA PAHs & - & 83.84 \\
\hline
\end{tabular}

in the presence of biochar in soil and suggested the greater degradation of less strongly sorbed compounds because of the reduced availability of strongly sorbed compounds in the presence of biochar in soil [36]. Results of the current study indicate that transport and leaching of naphthalene from unamended soil is more likely governed by dissolution in water rather than colloidal transport or other mechanisms.

\section{Leaching and Release Behavior of Fluorene}

Pulverized biochar was more effective than crushed biochar in immobilization of fluorene in soil. The aqueous concentration of phenanthrene, with the same number of aromatic rings in its structure as fluorene, was used as a measure of the effect of Pinus radiata-derived biochar on the sorption of PAHs in soil by Zhang et al. (2010), where the addition of 0.1-0.5 percent of biochar increased the soil sorption capacity of phenanthrene by one order of magnitude relative to the unamended soil [37]. One probable reason that caused higher performance of pulverized biochar in sorption and immobilization of fluorene in this study compared to the obtained results by Zhang et al. (2010) [37] for phenanthrene might be the higher application rate of biochar in the present research. An increase in biochar content of soil may enhance its performance in sorption and immobilization of $\mathrm{PAH}$ compounds such as fluorene in soil, as observed in this study by applying $5 \%$ pulverized biochar. Pulverized biochar showed slightly higher effectiveness than granular activated carbon in immobilization of fluorene in soil. Less homogeneous distribution of activated carbon in column B4 and therefore longer distances between activated carbon granules within the soil compared to column B3 (in which biochar was used in pulverized form) is likely to be responsible for less effectiveness of activated carbon to immobilize fluorene in soil in comparison with pulverized biochar.

\section{Leaching and Release Behavior of Pyrene}

Pyrene is shown to be more bioavailable in low organic matter soils than those with higher content of organic matter [38], implying the probable impact of carbon addition to soil on pyrene stabilization in soil through organic amendment as observed in this study for pulverized biochar and activated carbon. Declining concentrations of a solute indicate a non-equilibrium condition in column. The shift between equilibrium and non-equilibrium conditions depends on various parameters like flow velocity, grain size, diffusion distance, and sorption capacity. The concentration of a compound in the column effluent may decrease due to depletion of a given compound or due to non-equilibrium conditions established in the column [26]. Diminishing concentrations of leached PAHs were observed in some cases in this study, e.g., for pyrene in column B4, suggesting evolution of non-equilibrium condition in columns but most likely not the depletion of the contaminants as desorption and release of most studied PAHs lasted even at higher LS ratios.

\section{Leaching and Release Behavior of Benzo(b)Fluoranthene}

Results of the present study showed strong sorption of PAHs in unamended soil, especially for higher molecular weight PAHs, e.g., benzo(b)fluoranthene. Benzo(b)fluoranthene is a high-molecular weight PAH compound that is usually present in PAH mixtures. It has a high $\mathrm{K}_{\mathrm{ow}}$ value and is not easily biodegradable, thus may be considered a long-term threat to water resources. Since benzo(b)fluoranthene has been shown to be present in the soil (Table 4), a negligible amount of leached benzo(b) fluoranthene advocates strong sorption of that to soil and/ or a small release rate of benzo(b)fluoranthene into water. Strong sorption of benzo(a)pyrene (with the same number of benzene rings as benzo(b)fluoranthene) to soil was reported by Daryabeigi Zand et al. (2010) [39].

For PAHs with low solubility, i.e., more hydrophobic compounds with higher $\mathrm{K}_{\mathrm{ow}}$ values such as the 5- and 6-ring PAHs, the dissolution may last for a very long time and the aqueous concentrations might be constant for several weeks $[28,40]$ as observed for benzo(b)fluoranthene in this research at higher LS ratios. Desorption and leaching of benzo(b)fluoranthene in the presence of crushed biochar was enhanced by eight orders of magnitude, implying a high risk of groundwater contamination with high molecular weight PAHs when biochar is applied to soil in crushed form. It seems that facilitated transport of benzo(b)fluoranthene attached to biochar particles through leaching of the mobilized biochar particles is the most probable explanation for such an increase in aqueous concentrations of benzo(b)fluoranthene in the presence of crushed biochar in soil.

A study by MacKay and Gschwend (2001) evaluated concentrations of polycyclic aromatic hydrocarbons (PAHs) in groundwater at a coal tar site. They reported strong field evidence indicating colloid-facilitated transport of PAHs in groundwater and assumed humic-bound PAHs are as mobile as the dissolved PAHs and concluded that the release of some PAH compounds from the tar source was greater than estimates based solely on tar-water partitioning predictions. They observed concentrations 
of benzo(a)pyrene up to 16 times greater than tar-water equilibrium concentrations [41]. The release of benzo(b) fluoranthene was shown to be negligible in most cases (Fig. 2d), suggesting high hydrophobicity and strong sorption of benzo(b)fluoranthene, and hence no serious groundwater contamination risk during a leaching event (e.g., raining) if only water solubility of such compounds is taken into consideration.

\section{Leaching and Release Behavior of Indeno(1,2,3-cd)Pyrene}

Among the selected PAHs, indeno(1,2,3-cd)pyrene has the largest value of Log $\mathrm{K}_{\mathrm{ow}}$ (Table 2). Colloidfacilitated transport of indeno(1,2,3-cd)pyrene is likely to be the main reason for slightly mobilized indeno(1,2,3-cd) pyrene in the presence of crushed biochar in soil. However, mobilization of indeno(1,2,3-cd) pyrene in column B2 was negligible, demonstrating very strong sorption of indeno(1,2,3-cd)pyrene to soil under various scenarios evaluated in this research. Obtained results clearly show that the leaching fractions of initial amounts of the studied PAHs are declining with increasing hydrophobicity and molecular size, which is consistent with previous studies conducted on leaching of PAHs [1, 39, 42].

\section{Leaching and Release Behavior of Total PAHs}

In this research, the application of pulverized biochar and activated carbon to contaminated soil significantly affected the leaching behavior of the sum of 16 U.S. EPA PAHs. In total, less than one percent of the initial soil content of PAHs was released into percolates in both pulverized biochar-amended soil and activated carbonamended soil. In addition, comparing the released amount of total PAHs with the initial solid phase content of PAHs in soil would suggest that only $6.69 \%$ of the total PAHs were mobilized and leached from unamended contaminated soil during the leaching event, implying strong sorption of PAH compounds to soil. The presence of charcoal and activated carbon has been shown to increase the sorption of hydrophobic organic compounds (HOCs) in soils and sediments by 1 to 3 orders of magnitude [43]. Denyes et al. (2013) [22] has reported enhanced sorption of PCBs in soil amended with biochar and activated carbon.

The slightly higher performance observed in this study for activated carbon compared to pulverized biochar in some cases (e.g., for naphthalene) may be attributed to higher organic carbon content of activated carbon than biochar. The surface area of an organic amendment can also affect its sorption capacity. Chen et al. (2008) [44] determined the surface area of biochars at different pyrolytic temperatures and found that biochars pyrolyzed at $700^{\circ} \mathrm{C}$ had almost half of the surface area of a commercial activated carbon. In general, biochar and activated carbon have higher surface area than native soil organic matter, which results in a greater sorption capacity of organic contaminants $[45,46]$ such as PAHs. Based on the results of the present study, pulverized biochar and activated carbon demonstrated promising performance to reduced leaching and the release of the sum of 16 U.S. EPA PAHs from soil, and helped further immobilization of PAH compounds in soil, which is significantly favorable in terms of soil remediation.

\section{Effect of Biochar Particle Size}

A significant difference was observed between the performance of crushed and pulverized biochar in immobilization of most of the studied PAHs in soil, implying the key role of biochar particle size in controlling their fate in soil. For instance, results showed that reducing biochar particle size significantly enhanced biochar performance in stabilizing fluorene in soil, and reduced the cumulative release of that into water by 10 times. The cumulative release of the sum of 16 EPA PAHs was reduced by only $11 \%$ in the presence of crushed biochar (B2) compared to the unamended soil. Comparing the results for columns B2 and B3 reveals that a reduction in biochar particle size lowered the cumulative release of the 16 EPA PAHs by roughly seven orders of magnitude, signifying the importance of biochar particle size in sorption and immobilization of PAHs in soil through providing effective contact between PAH compounds and biochar particles. Reducing activated carbon particle size increased its effectiveness in sorption of PCBs in a PCBcontaminated sediment [47]. Brandli et al. (2008) [48] reported that the application of $2 \%$ activated carbon in granular and powder forms can reduce $\mathrm{PAH}$ concentrations in water phase by $3-64 \%$ and $63-99 \%$, respectively. The sorption properties may be significantly influenced by the particle size of an adsorbent [49], which can affect mobilization and leaching of contaminants from soil.

Results of the present study revealed more significant influence of biochar particle size on mobilization and leaching of higher molecular weight PAHs from soil. In other words, the higher the PAH molecular weight, the greater the role of biochar particle size in leaching and release of PAHs from soil. Biochar particle size effect on the fate of persistent organic contaminants in biocharamended soil is worth further investigation.

\section{Contribution of DOC and Turbidity to Mobilization of PAHs}

The application of pulverized biochar and activated carbon reduced leaching of dissolved organic matter from soil over the course of the leaching experiment (Fig. 4a), suggesting strong sorption of very fine particles (generally less than $0.45 \mu \mathrm{m}$, which is usually referred to as "dissolved" particles) to fine biochar particles as well as activated carbon granules. However, it can be inferred from the findings of the current research that DOC may play a role in mobilization and release of benzo(b)fluoranthene at lower LS ratios in the presence of both crushed and pulverized biochar (columns B2 and B3). 
Dissolved organic carbon may act as a carrier for organic pollutants such as PAHs and enhance their mobilization and transport in groundwater, soil, and other porous media [50]. A decrease in DOC content of column effluents through the addition of pulverized biochar and activated carbon to soil observed in the present study can reduce leaching of DOC-associated PAHs into water. Pulverized biochar and activated carbon granules demonstrated almost comparable results in DOC immobilization within the columns, with a slightly higher immobilization rate for the activated carbon. Apparent solubility of some PAHs may be enhanced in the presence of DOC in soil as some PAH compounds can be sorbed on dissolved organic matter. Dissolved organic matter (DOM) may exert two different impacts on the sorption of organic solutes by sorbent surfaces; they can reduce the sorption due to solubilization impacts and competition on the sorbent sites and/or increase the sorption when the solute-DOM complex has more affinity with the sorbent than the organic solute itself [51]. Initial rapid decrease in DOC concentration of column effluents could be caused by depletion of highly soluble organic carbon resources in soil.

Results indicated that mobilization of PAHs through leaching of dissolved organic carbon is more likely to occur at initial stages of a leaching event in both the presence and absence of an organic amendment in soil. In general, organic amendment of contaminated soil might reduce leaching of DOC from soil into water, as observed in the current research, suggesting reducing the risk of leaching of DOC-associated PAHs in contaminated sites through organic amendment of soil.

Organic amendment of contaminated soil enhanced turbidity levels in column leachates in this study. However, only a slight increase in turbidity was exerted at higher LS ratios when activated carbon was applied to the soil (Fig. $4 \mathrm{~b}$ ). The influence of the amount of mobilized suspended particles as well as DOC concentration on mobility of hydrophobic organic compounds has been reported in the literature $[52,53]$. Suspended solids have been shown to have an important role in carrying a wide variety of pollutants, especially hydrophobic organic compounds in porous media [54]. Higher molecular weight PAHs are strongly hydrophobic and hardly mobilized by only water flow within soil as observed in this study. One possible mechanism by which higher molecular weight PAHs are mobilized and leached from soil would be their transport on suspended solids present in soil. Increase in mobilization and release of pyrene, benzo(b)fluoranthene and indeno(1,2,3-c,d)pyrene from soil was observed in this study after the addition of crushed biochar to soil, which may be attributed to their facilitated transport by suspended solids associated with biochar particles. Colloid-facilitated transport described as a transport process in which colloidal particles served as a transport vector of contaminants can play a role in transport of strongly sorbing solutes in a porous media $[34,55]$, as observed for pyrene, benzo(b) fluoranthene, and indeno(1,2,3-c,d)pyrene in this study - particularly in the presence of crushed biochar in soil.
Pyrene association with humic acids has been reported by Mackay and Gschwend (2001) [41].

Biochar particle-associated migration of benzo(b) fluoranthene was also observed in the presence of pulverized biochar in soil. Increased desorption and leaching of strongly sorbed contaminants from soil through colloid-facilitated transport has also been reported in the literature [34, 55-56]. However, results of the present study indicated that colloid-facilitated transport of the PAHs as a result of increase in turbidity levels of leachates due to the application of activated carbon could not overcome strong sorption of the studied PAH compounds, including indeno(1,2,3-c,d)pyrene to activated carbon. In other words, biochar particles might be responsible for mobilization of higher molecular weight PAHs such as benzo(a)pyrene and facilitate their transport within soil in contaminated sites amended with biochar, while this might not necessarily be the case for soils amended with activated carbon. The initial turbidity level in effluent of column B2 was six times greater than that of column B3, suggesting the key role of biochar particle size in controlling leaching of colloidal matters from biocharamended soil at early stages of a leaching event.

\section{Conclusions}

Leaching and release of naphthalene, fluorene, and pyrene were markedly affected by the addition of biochar and activated carbon to soil; however, leaching behavior of higher molecular weight PAHs (i.e., benzo(b) fluoranthene and indeno(1,2,3-c,d)pyrene) was not altered in the presence of activated carbon and pulverized form of biochar to a great extent. Relatively high initial concentrations of the studied PAHs with two, three, and four rings were observed in leachate of column B1 in which no organic amendment was applied. The addition of pulverized biochar and activated carbon to soil reduced concentrations of naphthalene, fluorine, and pyrene in aqueous phase considerably, during the leaching process. The influence of biochar particle size on leaching behavior of PAHs in biochar-amended soil - which has not been addressed previously - revealed the key role of biochar particle size in controlling leaching and fate PAHs in amended soil. In this study, crushed biochar caused mobilization of highly hydrophobic compounds, i.e., benzo(b)fluoranthene and indeno(1,2,3-c,d)pyrene in soil.

Based on the obtained results, the DOC-associated release of the PAHs, especially low molecular weight PAHs, is more likely to occur in the unamended soil and amended soil with crushed biochar. Leaching of dissolved organic matter decreased when pulverized biochar and activated carbon were applied. Facilitated transport of some PAHs, especially higher molecular weight PAHs through suspended solids, was observed in this research. The addition of biochar in both forms and activated carbon to soil enhanced turbidity levels in all cases. Results demonstrated a considerable increase in mobilization and release of pyrene, benzo(b)fluoranthene, 
and indeno(1,2,3-c,d)pyrene in the presence of crushed biochar in soil, mainly due to their facilitated transport by suspended colloids associated with biochar particles.

Over the course of the experiment, up to the LS ratio of $4 \mathrm{~L} \mathrm{Kg}^{-1}$, only $6.69 \%$ of the total initial amounts of PAHs in the soil was mobilized and leached under the worst conditions (unamended soil). In addition, the leaching behavior of the sum of 16 U.S. EPA PAHs was not the same as individual PAH compounds, implying the significance of establishing remediation strategies and decisionmaking based on characteristics of an individual organic compound present in soil and its leaching behavior, rather than only relying on the total concentration of a group of contaminants, e.g. PAHs that comprise various aromatics with widely diverse hydrophobicity and sorption characteristics in soil. Marginal variation in $\mathrm{pH}$ values due to the addition of organic amendments to soil did not affect leaching behavior of PAHs markedly; however, further investigation of the role of environmental conditions on desorption and release of PAHs in organic amended contaminated soil is suggested.

Activated carbon and pulverized biochar showed comparable performance in reducing $\mathrm{PAH}$ leaching from contaminated soil. Results showed that organic amendment of soil using activated carbon and pulverized biochar can be considered as effective and promising remedial methods to control and reduce PAH leaching from contaminated soil into groundwater resources. Based on the obtained results, pulverized biochar may be considered as a less expensive alternative to activated carbon in reducing mobilization and release of PAHs from contaminated soils into water. Further field investigations over extended periods of time might be helpful to gain real-world scale insight into the impact of pulverized biochar and activated carbon in immobilization of PAHs in soil.

\section{Acknowledgements}

The authors would like to sincerely thank the Alexander von Humboldt Foundation to provide sponsorship and acknowledge the Labor of Applied Geosciences, University of Tübingen, especially Renate Seelig, for the skilled laboratory support. The first author would also like to thank the Faculty of Environment, University of Tehran for the support.

\section{References}

1. ENELL A., REICHENBERG F., WARFVINGE P., EWALD G. A column method for determination of leaching of polycyclic aromatic hydrocarbons from aged contaminated soil. Chemosphere 54, 707, 2004.

2. GILBERT D., JAKOBSEN H.H., WINDING A., MAYER, P. Co-transport of polycyclic aromatic hydrocarbons by motile microorganisms leads to enhanced mass transfer under diffusive conditions. Environ. Sci. Technol. 48, 4368, 2014.
3. SUN M., LUO Y., CHRISTIE P., JIA Z., LI Z., TENG Y. Methyl-beta-cyclodextrin enhanced biodegradation of polycyclic aromatic hydrocarbons and associated microbial activity in contaminated soil. J. Environ. Sci. 24 (5), 926, 2012.

4. WICK A.F., HAUS N.W., SUKKARIYAH B.F., HAERING K.C., DANIELS W.L. Remediation of PAH-contaminated soils and sediments: a literature review. Virginia Polytecnic Institute; 6, USA, 2011.

5. ENELL A., FUHRMAN F., LUNDIN L., WARFVINGE P., THELIN G. Polycyclic aromatic hydrocarbons in ash: determination of total and leachable concentrations. Environ. Pollut. 152, 285, 2008.

6. BANSAL V., KIM K.H. Review of PAH contamination in food products and their health hazards. Environ. Int. 84, 26, 2015.

7. KIM K.H., JAHAN S.A., KABIR E., BROWN R.J. A review of airborne polycyclic aromatic hydrocarbons (PAHs) and their human health effects. Environ. Int. 60, 71, 2013.

8. GUANSEKARA A.S., XING B. Sorption and desorption of naphthalene by soil organic matter: importance of aromatic and aliphatic components. J. Environ. Qual. 32, 240, 2003.

9. MAIER U., GRATHWOHL P. Numerical experiments and field results on the size of steady state plumes. J Contam. Hydrol. 85, 33, 2001.

10. LIU R., ZHAO D. Reducing leachability and bioaccessibility of lead in soils using a new class of stabilized iron phosphate nanoparticles. Water Res. 41, 2491, 2007.

11. SI Y., ZHANG J., WANG S., ZHANG L., ZHOU D. Influence of organic amendment on the adsorption and leaching of ethametsulfuron-methyl in acidic soils in China. Geoderma 130, 66, 2006.

12. RAZZAQUE M.M., GRATHWOHL P. Predicting organic carbon-water partitioning of hydrophobic organic chemicals in soils and sediments based on water solubility. Water Res. 42(14), 3775, 2008.

13. CHEN B., YUAN M. Enhanced sorption of polycyclic aromatic hydrocarbons by soil amended with biochar. J Soil Sediment, 11, 62, 2004.

14. WEN B., LI R.J., ZHANG S.Z., SHAN X.Q., FANG J., XIAO K., KHAN S.U. Immobilization of pentachlorophenol in soil using carbonaceous material amendments. Environ. Pollut. 157, 968, 2009.

15. LOHMANN R. The Emergence of Black Carbon as a SuperSorbent in Environmental Chemistry: The End of Octanol? Environ. Forensics 4 (3), 161, 2003.

16. REID B.J., PICKERING F.L., FREDDO A., WHELAN M.J., COULON F. Influence of biochar on isoproturon partitioning and bioaccessibility in soil. Environ. Pollut. 181, 44, 2013.

17. LEHMANN J., RILLIG M.C., THIES J., MASIELLO C.A., HOCKADAY W.C., CROWLEY D. Biochar effects on soil biota-A review. Soil Biol. Biochem. 43, 1812, 2011.

18. SOHI S., KRULL E., LOPEZ-CAPEL E., BOL R. A review of biochar and its use and function in soil. Adv. Agron. 105, 47, 2010

19. AMSTAETTER K., EEK E., CORNELISSEN G. Sorption of PAHs and PCBs to activated carbon: Coal versus biomassbased quality. Chemosphere 87, 573, 2012.

20. BEESLEY L., MORENO-JIMÉNEZ E., GOMEZ-EYLES J.L., HARRIS E., ROBINSON B., SIZMUR T. A review of biochars' potential role in the remediation, revegetation and restoration of contaminated soils. Environ. Pollut. 159, 3269, 2011.

21. AYOTAMUNO M.J., KOGBARA R.B., OGAJI S.O.T., PROBERT S.D. Petroleum contaminated groundwater: 
remediation using activated carbon. Appl. Energ. 83 (11), 1258, 2006.

22. DENYES M.J., RUTTER A., ZEEB B.A. In situ application of activated carbon and biochar to PCB-contaminated soil and the effects of mixing regime. Environ. Pollut. 182, 201, 2013.

23. GOMEZ-EYLES J.L., SIZMUR T., COLLINS C.D., HODSON, M.E. Effects of biochar and the earthworm Eisenia fetida on the bioavailability of polycyclic aromatic hydrocarbons and potentially toxic elements. Environ. Pollut. 159 (2), 616, 2011.

24. BEESLEY L., MORENO-JIMENEZ E., GOMEZ-EYLES J.L. Effects of biochar and greenwaste compost amendments on mobility, bioavailability and toxicity of inorganic and organic contaminants in a multi-element polluted soil. Environ. Pollut. 158 (6), 2282, 2010.

25. GRATHWOHL P., VAN DER SLOOT H. Groundwater Risk Assessment at Contaminated Sites (GRACOS): Test Methods and Modeling Approaches. RSC Publishing, Cambridge. 2007.

26. GRATHWOHL P., SUSSET B. Comparison of percolation to batch and sequential leaching tests: Theory and data. Waste Manage. 29, 2681, 2009.

27. DIN 19528, Elution von Feststoffen - Perkolationsverfahren zur gemeinsamen Untersuchung des Elutionsverhaltens von anorganischen und organischen Stoffen (Leaching of solid materials - Percolation method for the joint examination of the leaching behaviour of organic and inorganic substances), German Standard Methods, Germany, 2009.

28. KALBE U., BERGER W., ECKARDT J., SIMON F.G. Evaluation of leaching and extraction procedures for soil and waste. Waste Manage. 28, 1027, 2008.

29. ZANIST K. Comparison of Leaching Tests for PAHs Contaminated Soils. MSc Thesis, Center for Applied Geosciences, University of Tubingen; 2-19, Germany, 2008.

30. CEN. CEN/TS 14405. Characterization of Waste-Leaching Behaviour Tests-Up-flow Percolation Test (under specified conditions), European Committee for Standardisation; pp.140, Belgium, 2004

31. BOJES H.K., POPE P.G. Characterization of EPA's 16 priority polycyclic aromatic hydrocarbons (PAHs) in tank bottom solids and associated contaminated soils at oil exploration and production sites in Texas. Regul. Toxicol. Pharm. 47, 288, 2007.

32. UNWIN J., COCKER J., SCOBBIE E., CHAMBERS H. An Assessment of Occupational Exposure to Polycyclic Aromatic Hydrocarbons in the UK. Ann. Occup. Hyg. 50 (4), 395, 2006.

33. GARON D., SAGE L., WOUESSIDJEWE D., SEIGLEMURANDI F. Enhanced degredation of fluorene in soil slurry by Absidia cylindrospora and maltosyl-cyclodextrin. Chemosphere 56, 159, 2004.

34. NGUELEU S.K., GRATHWOHL P., CIRPKA O.A. Effect of natural particles on the transport of lindane in saturated porous media: Laboratory experiments and model-based analysis. J Contam. Hydrol. 149, 13, 2013.

35. MARCHAL J., SMITH K.E.C., REIN A., WINDING A., JONGE L.W., TRAPP S., KARLSON U.G. Impact of activated carbon, biochar and compost on the desorption and mineralization of phenanthrene in soil. Environ. Pollut. 181, 200, 2013.

36. BUSHNAF K.M., PURICELLI S., SAPONARO S., WERNER D. Effect of biochar on the fate of volatile petroleum hydrocarbons in an aerobic sandy soil. J Contam. Hydrol. 126, 208, 2011.
37. ZHANG H., LIN K., WANG H., GAN J. Effect of Pinus radiata derived biochars on soil sorption and desorption of phenanthrene. Environ. Pollut. 158, 2821, 2010.

38. OLU-OWOLABI B.L., DIAGBOYA P.N., ADEBOWALE K.O. Evaluation of pyrene sorptionedesorption on tropical soils. J. Environ. Manage. 137, 1, 2014.

39. DARYABEIGI ZAND A., GRATHWOHL P., NABI BIDHENDI G.R., MEHRDADI N. Determination of leaching behavior of polycyclic aromatic hydrocarbons from contaminated soil by column leaching test. Waste Manage. Res. 28, 913, 2010.

40. SUSSET B., GRATHWOHL P. Column leaching test for groundwater risk assessment: concept, interpretation of results and reproducibility; European lysimeter station reports, 2008. Available at: http://www.lysimeter.at/HP EuLP/reports/germany/Susset_lab.pdf.

41. MACKAY A.A., GSCHWEND P.M. Enhanced concentrations of PAHs in groundwater at a coal tar site. Environ. Sci. Technol. 35 (7), 1320, 2001.

42. MARDBERG A.C. Adsorption of polycyclic aromatic hydrocarbons (PAH) on Sphagnum moss peat. MSc Thesis, Chalmers University of Technology; 12, Sweden, 2006.

43. CORNELISSEN G., GUSTAFSSON Ö., BUCHELI T D., JONKER M.T.O., KOELMANS A.A., NOORT P.C.M. Extensive sorption of organic compounds to black carbon, coal, and kerogen in sediments and soils: mechanisms and consequences for distribution, bioaccumulation, and biodegradation. Environ. Sci. Technol. 39, 6881, 2005.

44. CHEN B.L., ZHOU D.D., ZHU L.Z. Transitional adsorption and partition of nonpolar and polar aromatic contaminants by biochars of pine needles with different pyrolytic temperatures. Environ. Sci. Technol. 42 (14), 5137, 2008.

45. ANDERSON N., JONES J.G., PAGE-DUMROESE D., MCCOLLUM D., BAKER S., LOEFFLER D., CHUNG W. A comparison of producer gas, biochar, and activated carbon from two distributed scale thermochemical conversion systems used to process forest biomass. Energies 6, 164, 2013.

46. PARK J., HUNG I., GAN Z., ROJAS O.J., LIM K.H., PARK S. Activated carbon from biochar: Influence of its physicochemical properties on the sorption characteristics of phenanthrene. Bioresour. Technol. 149, 383, 2013.

47. ZIMMERMAN J.R., WERNER D., GHOSH U., MILLWARD R.N., BRIDGES T.S., LUTHY R.G. Effects of dose and particle size and particle size on activated carbon treatment to sequester polychlorinated biphenyls and polycyclic aromatic hydrocarbons in marine sediments. Environ. Toxicol. Chem. 24, 1594, 2005.

48. BRANDLI R.C., HARTNIK T., HENRIKSEN T., CORNELISSEN G. Sorption of native polyaromatic hydrocarbons (PAH) to black carbon and amended activated carbon in soil. Chemosphere 73, 1805, 2008.

49. JARADAT A., FOWLER K., GRIMBERG S., HOLSEN T. Transport of Colloids and Associated Hydrophobic Organic Chemicals through a Natural Media Filter. J. Environ. Eng. 135(1), 36, 2009.

50. JOSKO I., OLESZCZUK P., PRANAGAL J., LEHMANN J., XING B., CORNELISSEN J. Effect of biochars, activated carbon and multiwalled carbon nanotubes on phytotoxicity of sediment contaminated by inorganic and organic pollutants. Ecol. Eng. 60, 50, 2013.

51. CELIS R., REAL M., HERMOSIN M.C., CORNEJO J. Desorption, persistence, and leaching of dibenzofuran in European soils. Soil Sci. Soc. Am. J. 70, 1310, 2006.

52. PERSSON Y., HEMSTROM K., OBERG. L., TYSKLIND M., ENELL A. Use of a column leaching test to study the 
mobility of chlorinated HOCs from a contaminated soil and the distribution of compounds between soluble and colloid phases. Chemosphere 71, 1035, 2008.

53. KIM Y.J., LEE D.H., OSAKO M. Effect of dissolved humic matters on the leachability of PCDD/Fs from fly ash - laboratory experiment using Aldrich humic acid. Chemosphere, 47, 599, 2002.

54. RÜNGER H., SCHWIENTEK M., BECKINGHAM B., KUCH B., GRATHWOHL P. Turbidity as a proxy for total suspended solids (TSS) and particle facilitated pollutant transport in catchments. Environ. Earth Sci. 69 (2), 373, 2013.

55. GROLIMUND D., BORKOVEC M. Colloid-Facilitated Transport of Strongly Sorbing Contaminants in Natural Porous Media: Mathematical Modeling and Laboratory Column Experiments. Environ. Sci. Technol. 39 (17), 6378, 2005.

56. CHENG T., SAIERS J.E. Colloid-Facilitated Transport of Cesium in Vadose-Zone Sediments: The Importance of Flow Transients. Environ. Sci. Technol. 44 (19), 7443, 2010. 